Research Report No. 33/2013

\title{
The Equator Principles: Evaluating the Exposure of Commercial Lenders to Socio-Environmental Risk
}

Andrian Lozinski

Follow this and additional works at: http:/ / digitalcommons.osgoode.yorku.ca/clpe

\section{Recommended Citation}

Lozinski, Andrian, "The Equator Principles: Evaluating the Exposure of Commercial Lenders to Socio-Environmental Risk" (2013). Comparative Research in Law \& Political Economy. Research Paper No. 33/2013.

http://digitalcommons.osgoode.yorku.ca/clpe/279 


\section{OSGOODE}

OSGOODE HALL LAW SCHOOL YOR K U N I VERSITY

\section{OSGOODE HALL LAW SCHOOL}

Comparative Research in Law \& Political Economy

RESEARCH PAPER SERIES

Research Paper No. 33/2013

The Equator Principles: Evaluating the Exposure of Commercial Lenders to Socio-Environmental Risk

Andrian Lozinski

Editors:

Peer Zumbansen (Osgoode Hall Law School, Toronto, Director Comparative Research in Law and Political Economy)

John W. Cioffi (University of California at Riverside)

Leeanne Footman (Osgoode Hall Law School, Toronto, Production Editor)

Comparative Research in Law \& Political Economy 


\title{
Articles
}

\section{The Equator Principles: Evaluating the Exposure of Commercial Lenders to Socio-Environmental Risk}

\author{
By Andrian Lozinski*
}

\section{A. Introduction}

As a system of managing environmental and social risk in the sector of large-scale international project finance, the Equator Principles (EPs) have generated increased interest and critical engagement in the private, public, and academic spheres. Particular research in the field of transnational governance is especially concerned with assessing the degree in which private and public actors are revolutionizing the methods and procedures of governance in the wake of the decline of the welfare state, and rise of the postregulatory state. Social scientists and legal theorists alike have begun analyzing the effects of a shift in the "emphasis of control, to a greater or lesser degree, from traditional bureaucratic mechanisms towards instruments of regulation." ${ }^{1}$ Within this context, the EPs present an opportunity to analyze and assess the structure, procedures and effectiveness of a self-regulatory governance system, voluntarily established by private actors in the international project finance sector, to mitigate social and environmental risks.

Some scholars suggest that the retention of risk on the balance sheet of project finance lenders has been an important instigator to the establishment of a regulatory system where the banks pledge to act in a manner that is "both responsible and sustainable" in managing potential negative social and environmental risks. ${ }^{2}$ This, of course, presupposes that the risk management procedures are adequately designed to manage the unique context of social and environmental exposure in large infrastructure financing. The distinctive nature of the project finance sector results from the fact that it is dominated by non-recourse financing, which provides an additional layer of structural regulation. Within this framework, and with a specific focus on the vulnerabilities of the project lender, this paper aspires to investigate whether the mitigation procedures under the EPs are well

\footnotetext{
•M.A., J.D. Candidate, Osgoode Hall Law School. Email: andrian.lozinski@osgoode.yorku.ca.

${ }^{1}$ Colin Scott, Regulation in the Age of Governance: the Rise of the Post Regulatory State, in THE POLITICS OF Regulation: INSTITUtions AND Regulatory Reforms for the Age OF GoVernanCE 145, 148 (Jacint Jordana \& David LeviFaur eds., 2004).

2 John Conley \& Cynthia Williams, Global banks as Global Sustainability Regulators?: The Equator Principles, $33 \mathrm{~L}$. \& POL'Y 1, 2 (2011).
} 
suited to address the manner in which socio-environmental risks may manifest within the context of non-recourse financing.

Section B will introduce the EPs with the purposes of identifying the structural allocation of responsibility for risk mitigation between the lender and sponsor-borrower under the EP framework. Of primary importance to this investigation is the temporal framework in which socio-environmental risks are identified and the normative requirements and procedures involved for project-lenders and sponsor-borrowers in mitigating these risks. Section $C$ will then assess how enacting the EPs have altered the risk management regulatory framework for the large-scale infrastructure sector.

Section D will explore the structural constraints of non-recourse financing and attempt to determine whether the EP procedures are adequately equipped to manage the lender's peak exposure to socio-environmental risk as determined by the structure of the loan term. This form of financing is an important determinant of a project participant's risk exposure which provides that any attempt to manage the associated risks should be informed by, and responsive to, the system within which it functions.

Section E will then assess the ability of the EPs to effectively capture and mitigate the project lender's socio-environmental risk exposure and make recommendations to address any shortcomings identified in this investigation. As Conley and Williams assert that "changes in credit market behaviour could ultimately be a much more powerful mechanism for changing companies' social behaviour," ${ }^{3}$ then perhaps a more complete understanding of the lender's exposure to socio-environmental risks could provide for more responsible and sustainable post-regulatory governance.

\section{B. The Equator Principles: Lender-Borrower Risk Allocation}

The EPs are promoted as "a credit risk management framework for determining, assessing and managing environmental and social risk in project finance transactions." ${ }^{44}$ Several important questions arise regarding which types of risk are being captured within the EP framework, who is responsible for ascertaining and assessing those risks, and what are the procedures utilized to identify and manage the risks to a given project. This portion of the analysis will focus on assessing the manner in which responsibility over certain forms of risk are allocated in order to understand the normative requirements and procedures that lenders and sponsors of large-scale construction and infrastructure projects are required to undertake in order to move forward with project financing. It should be noted that the EPs

\footnotetext{
${ }^{3}$ Id. at 5 .

4 Equator Principles, "About the Equator Principles", available at: http://www.equatorprinciples.com/index.php/about-ep (last accessed: 1 December 2012).
} 
evolved from the International Finance Corporation (IFC) Performance Standards on Social and Environmental Sustainability (Performance Standards), which provide the contextual base for current regulatory procedures.

The first EP requires the bank to conduct an assessment of the environmental and social risks perceived to affect any proposed project for financing. This requires the lender to categorize each project accordingly:

I. Category A - Projects with potential significant adverse social and environmental impacts that are diverse, irreversible or unprecedented

II. Category B - Projects with potential limited adverse social or environmental impacts that are few in number, generally site-specific, largely reversible and readily addressed through mitigation measures; and

III. Category C - Projects with minimal or no social or environmental impacts. ${ }^{5}$

It is pertinent to question why participating banks would be concerned about the degree of socio-environmental risk involved for each proposed project to such an extent that the financier is compelled to undertake a preliminary assessment of the overarching level of project risk. As Amalric explains: "environmental risks may have a direct bearing on project returns, when, for instance, the life-expectancy of a dam is shortened by unexpected ecological processes; and social risks, in the form of local resistance against unpopular projects can delay construction and normal operations (e.g. attacks against pipelines). ${ }^{\prime 6}$ In other words, it is not environmental and social risks in themselves that the banks are focused on. Instead, it is the consequences (actual or potential) to the lender's ability to recover and profit from the invested capital as a result of unanticipated and uncontrolled environmental and social phenomena.

The bank's initial due diligence in assessing the environmental and social risks is then provided to the sponsor-borrower, under Principle 2 of the EPs. For every project labeled under category A or B, the borrower is required to undertake "a Social and Environmental Assessment ("Assessment") to address, as appropriate, and to the (lender's) satisfaction, the relevant social and environmental risks delineated by the lender". ${ }^{7}$ The borrower is

\footnotetext{
${ }^{5}$ Equator Principles, Equator Principles: A Financial Industry Benchmark for Determining, Assessing and Managing Social and Environmental Risk in Project Finance 1, 2-7 (2006), available at: http://www.equatorprinciples.com/index.php/the-eps-and-official-translations (last accessed: 1 December 2012).

${ }^{6}$ Franck Amalric, The Equator Principles: A Step Towards Sustainability?, 1 CENTER For CORPORATE RESPONSIBILITY AND SUSTAINABILITY WORKING PAPER SERIES 1, 9 (2005).

${ }^{7}$ Equator Principles, supra note 5, at 2.
} 
required to demonstrate to the lender in the Social and Environmental Assessment, under Principle 3, that the risks identified are being addressed in compliance with local and national law in High-income OECD countries. Appropriate IFC Performance Standards and Industry Specific Environmental Health and Safety Guidelines (EHS Guidelines) are to be alternatively utilized "for projects located in non-OECD countries, and those located in OECD countries not designated as High-income." ${ }^{8}$

Principle 4 requires the borrower to prepare an Action Plan (AP) to identify the company's means for mitigating the risks that were first identified by the lender, and further expanded upon by the borrower in the Assessment under Principle 2 and 3 . The AP is coupled with a Social and Environmental Management System, implemented by the sponsor to address "the management of these impacts, risks, and corrective action required to comply with applicable host country social and environmental laws and regulations, and requirements of the applicable Performance Standards and EHS Guideline, as defined in the AP." ${ }^{\prime 9}$

Principle 5 defines the consultation and disclosure requirements borrowers must undertake in targeted communities. Briefly, for high impact projects (category $A$ and some category B projects), the borrower is required to consult with the community in a "structured and culturally appropriate manner." ${ }^{10}$ This does not mean that the borrower must take heed of the concerns of the community, but simply that a process of "free, prior, and informed consultation" need be enacted for high-impact projects in order to satisfy the lender that there is an open dialogue with the community. ${ }^{11}$ This type of procedural mechanism, where the borrower is required to consult with the public to satisfy the bank that the community has been informed, seemingly provides a potential obvious source of heightened social risk for projects where the community's concerns are noted by the sponsor, but otherwise ignored.

Principle 6 requires the borrower to establish a grievance mechanism that is "scaled to the risks and adverse impacts of the project" in order to "receive and facilitate resolutions of concerns and grievances about the project's social and environmental performance raised by individuals or groups from among project-affected communities." ${ }^{12}$ The borrower is to alert the community about the grievance process, and is expected by the bank to make the mechanism transparent and accessible. Although there is a dearth of academic

\footnotetext{
${ }^{8}$ Equator Principles, supra note 5, at 3.

${ }^{9}$ Id.

${ }^{10}$ Id. at 4 .

${ }^{11}$ Id.

${ }^{12}$ Equator Principles, supra note 5, at 4.
} 
engagement assessing the effectiveness of any established grievance process, criticism regarding the lack of transparency under the EPs is frequently levied by non-governmental organizations (NGOs). ${ }^{13}$

Principle 7 requires the sponsor to acquire an expert and independent social and environmental assessment for all Category $A$ and suitable Category B projects. The cost of this principle is allocated to the sponsor, however, the benefit is provided to the lender as it is undertaken to "assist the (lender's) due diligence." ${ }^{14}$ What is most important is that the scope of the independent expert review is circumscribed by Principle 7 itself. The expert is not required to conduct an entirely independent assessment of the socioenvironmental risks pertinent to the project. The independent expert is instead charged with reviewing "the Assessment, AP and consultation process documentation." ${ }^{15}$ Essentially, this stage is constrained to a compliance review to satisfy the lender that the borrower's mitigation procedures are in compliance with Principles 1 to 4 of the EPs. The socio-environmental risks reviewed are prescribed and preselected by the Assessment and $\mathrm{AP}$, which means that there is no procedural requirement to re-evaluate or re-assess the associated risks or the effectiveness of the chosen mitigation procedures.

Principle 8 is highlighted as an "important strength"16 of the EPs as it requires all sponsors of high to medium impact projects to make compliance covenants with the lender. Essentially, the borrower promises to comply with (1) the host country's socio-economic laws and regulation, (2) the $A P,(3)$ periodic reporting requirements, and (4) the decommissioning plan where applicable.

While it appears that the banks have reserved remedial powers to both help bring the borrower back into compliance if it shirks the socio-environmental covenants, or exercise "remedies as they consider appropriate" ${ }^{17}$ in other undefined situations, this principle cannot be interpreted as an innovation in socio-environmental regulation unique to the EPs. This is due to the fact that the everyday operation of project finance requires a web of "detailed and complex contracts which specify the exact nature and duration of the relationships between various participants in the project." ${ }^{18}$ Principle 8 provides an

\footnotetext{
${ }^{13}$ Bank Track, The Outside Job: Turning the Equator Principles Towards People and Planet 1, 8 (2011) available at: http://www.banktrack.org/download/the outside job/111021 the outside job final.pdf (last accessed: 1 December 2012).

${ }^{14}$ Equator Principles, supra note 5, at 5.

${ }^{15}$ Id.

${ }^{16} / d$.

${ }^{17}$ Id.

${ }^{18}$ L. Michael Farrell, Principle-agency Risk in Project Finance, 21 INT'L. J. PROJ. MGMT. 547, 548 (2003).
} 
example of a generic behavioral-based contract often found in project finance, which is the type of contract that is most effective in situations where the party seeking to uphold the covenant can "completely prescribe and monitor the actions" of the other party. ${ }^{19}$ The lender is in this position because the sponsor must adopt the prescribed EP procedures as a condition for obtaining financing, while monitoring compliance through the contractually agreed upon disclosure and reporting requirements, permitting the sponsor to maintain an open line of credit. This provides that the project finance contract and the associated procedures prescribed by the bank are upheld, but it does not provide any additional socio-environmental protection for the affected community. At its most base level, Principle 8 is seemingly a simple acknowledgement of the privity of contract that exists between the lender and the borrower.

Principle 9 is the EP that provides for the aforementioned monitoring and reporting mechanism, which requires an independent environmental and social expert to verify the borrower's monitoring information in order to share it with the lender. ${ }^{20}$ Finally, Principle 10 requires the lender to publicly report annually "about its Equator Principles implementation processes and experience, taking into account appropriate confidentiality considerations. ${ }^{21}$ This last principle has equally been the subject of criticism by NGOs for lacking transparency.

\section{Altered Governance in the Project Finance Sector?}

This paper has briefly mentioned that the EPs have been strongly influenced by the IFC Performance Standards. This flows from the fact that the international project finance sector was previously subject to the governance of multilateral development banks (MDBs). It is therefore worth considering how the allocation of risk has shifted with a regulation system implemented and operated by commercial lenders.

Prior to the retreat of MDBs from the project-financing sector (most significantly the World Bank Group (WBG) and its privately directed arm, the IFC), the socio-environmental screening process would have been conducted by these institutions. The MDBs conducted the socio-environmental screening process "following strict social and environmental guidelines . . . developed over the past decade (1995-2005),"22 while providing a monitoring function, limited to the client sponsors approved for financing. This can be demonstrated, for example, by the IFC's stated roles and responsibilities:

\footnotetext{
${ }^{19}$ ld. at 553.

${ }^{20}$ Equator Principles, supra note 5, at 5.

${ }^{21} / d$. at 6.

${ }^{22}$ Amalric, supra note 6 , at 10 .
} 
IFC's role is to review the client's assessment; to assist the client in developing measures to avoid, minimize, mitigate or compensate for social and environmental impacts consistent with the Performance Standards; to categorize the project in order to specify IFC's institutional requirements to disclose to the public project-specific information; to help identify opportunities to improve social and environmental outcomes; and to monitor the client's social and environmental performance throughout the life of IFC's investment. ${ }^{23}$

In other words, the IFC provided its institutional resources and expertise directly to the risk management process throughout the course of the investment period.

The overall approach of the IFC was to conduct a social and environmental review on its own terms, taking into account the socio-environmental risks assessed by the project sponsor, and assessing them in relation to the overall financial and reputational risks of the project, and the benefits and contributions the investment provides for the host community. $^{24}$ In consideration of these combined factors, the IFC would delineate and assess the risks associated with the project and make its own internal decision in regards to the categorization of the socio-environmental impact (utilizing similar categories to those found in the EPS) in order to present the findings to the Board of Directors for their consideration and approval. ${ }^{25}$ This arrangement presented two layers of regulation, as the IFC project management team conducting the screening process was required to report their findings on the viability of the project to the IFC Board of Directors. The Board of Directors then had the task of evaluating the project within the context of the "IFC's mission . . . to promote sustainable private sector development in developing countries, helping to reduce poverty and improve people's lives." ${ }^{26}$

Once the Board of Directors had approved the financing for the project, the IFC continued to monitor the performance of its investment through a variety of ongoing reporting, inspection, review, and remedial mechanisms. ${ }^{27}$ The IFC did not rely on the project sponsor or an external independent expert to ensure compliance with its social and environmental sustainability policy. Under this system of socio-environmental risk management, the

${ }^{23}$ IFC, International Finance Corporations Policy on Social \& Environmental Sustainability, 2 (2006), available at: http://www.ifc.org/ifcext/sustainability.nsf/AttachmentsByTitle/pol_SocEnvSustainability2006/\$FILE/Sustainabilit yPolicy.pdf (last accessed: 1 December 2012).

${ }^{24}$ Id. at 3.

${ }^{25}$ Id. at 3-4.

${ }^{26} \mathrm{IFC}$, supra note 23 , at 1.

${ }^{27}$ Id. at 5-6. 
lender itself took on the responsibility and costs of assessing the viability of the project for funding, and then ensuring continual compliance with its own policies, developed to further the institution's purpose.

Although this IFC governance structure of screening and monitoring would be unevenly applied in the industry (as it would only apply to projects under the wings of the MDB itself) the primary advantage of this arrangement was the removal of the associated costs of the socio-environmental assessment and monitoring from commercial lenders who partnered with the MDB to finance the project. This benefit to commercial lenders was provided as a result of the syndicated nature of the majority of project finance loans. As outlined by Esty and Megginson,

A bank syndicate is a collection of banks that jointly extend a loan to a specific borrower ... Lending syndicates resemble pyramids with arranging banks (arrangers) at the top and providing banks (providers) at the bottom. Prior to closing a loan, the arranger (or mandated) banks meet with the borrower, perform a credit analysis, negotiate key terms and conditions, and prepare an information memorandum for providing banks. Once the key terms are in place, the arranging banks invite other banks to participate in the deal and allocate shares to them as they see fit. ${ }^{28}$

As MDBs previously assumed the role of arranger banks, and implemented their own socio-environmental risk assessment, the syndicated nature of the loan ensured that the costs (and associated responsibility) for developing, ascertaining, organizing, and directing a strategic plan for mitigating the socio-environmental risks was assumed completely by the MDB.

In sum, the result was a governance structure in which all variables for a given project were gathered and analyzed through the institutional expertise and centralized knowledge of an organization operating for the purpose of facilitating and monitoring socially and environmentally sustainable private sector development projects. Further, an added effect of such governance, aside from removing significant costs from commercial lenders, was to provide an important mechanism for signaling to commercial banks the "high quality" of certain sponsor projects due to the involvement of the IFC or other MDBs. ${ }^{29}$

Today, the governance structure implemented under the EPs is markedly different. The benefit of the newly expanded space for commercial lenders to act as arranging banks for project finance syndicates is seemingly accompanied by the added costs of managing the

\footnotetext{
${ }^{28}$ Benjamin Esty \& William Megginson, Creditor Rights, Enforcement, and Debt Ownership Structure: evidence from the Global Syndicated Loan Market, 38 J. OF FIN. QUANT. 1, 4 (2003).

${ }^{29}$ Amalric, supra note 6, at 10.
} 
socio-environmental risks in non-recourse financing that were previously assumed by the MDBs. As Amalric explains, the decision of the commercial banks to act collectively to implement the EPs may be as a result of "the inefficiency of decentralized screening . . . and the gains to be reaped by imposing screening costs onto project sponsors." ${ }^{30}$

It is evident how project-sponsors are required to assume the costs of the socioenvironmental assessment. Principle 1 of the EPs requires the lender to conduct a preliminary assessment of the potential socio-environmental impacts and generally categorizes the risk. After this stage, the costs shift to the borrower in Principles 2-4, who must prepare the Assessment, Action Plan, and Management System, to the satisfaction of the lender. ${ }^{31}$ A similar standard is in place for the remaining principles detailing the consultation and disclosure process, grievance mechanism, independent review, covenants, and independent monitoring and reporting requirements. The effect of this cost shift is that it fixes the assessment of risk and approved mitigation protocols to the earliest stages of project inception. It also results in a de facto decentralized screening process due to the fact that, outside of the ten EPs, the environmental screening and management process is conducted by the sponsor of each project. The entire risk management process then hinges on managing only those risks which can be foreseen when a project is initiated and the borrower generates the Assessment, AP and Management system. This is an inherently static temporal risk management framework. The regulatory framework is seemingly unable to account for unforeseen or significantly amplified social and environmental risks that may emerge in a sector with "largely unknown risks involved" and potential amortization periods of "up to 35 years."

The EPs are completely silent as to the responsibilities of the lender or borrower and procedures that must be followed where an unforeseen social or environmental risk emerges or a minimal or poorly categorized risk becomes significantly amplified. This regulatory gap may partially explain how some EP projects are certified as being "Equatorcompliant" despite ongoing criticism and challenges levied by NGOs for their devastating environmental and social effects. ${ }^{33}$

For the EP structure of regulation to meet the aspiration of being environmentally and socially responsible and sustainable in its current format, there is a concerted amount of pressure on the lender to ensure that the environmental and social risks that may emerge over the course of the loan are accurately and adequately captured by the borrower

${ }^{30}$ Id. at 11.

${ }^{31}$ Equator Principles, supra note 5, at 2.

${ }^{32}$ A. Ng \& Martin Loosemore, Risk Allocation in the Private Provision of Public Infrastructure, 25 INT'L J. OF PROJ. MGMT. 66, 68 (2007).

${ }^{33}$ Bank Track, supra note 13 , at 2. 
before approval of the loan is granted. The lenders satisfaction with the borrower's management plan is assessed against the internal social and environmental risk policies, procedures, and standards which lenders are required to introduce and implement under the EPs. ${ }^{34}$ However, the EPs simply allocate responsibility to each individual lender to implement their own policies and provide no guidance for standardization or benchmarks for assessing compliance or effectiveness. Where the governance of socio-environmental risks would have previously had a greater level of standardization for commercial lenders working within the established procedures of a MDB, the EPs result in a decentralization of knowledge as each Equator Principle Financial Institution (EFPI) develops its own idiosyncratic internal socio-environmental risk policies.

There is an absence of academic research on the policies and procedures that individual EPFIs, and commercial banks in general, utilize in assessing social and environmental risk factors associated with project financing loans. However, in an industry report for ISIS Asset Management on environmental credit risk factors, Coulson states that bank policies usually operate on two levels. The first approach consists of "overarching/crossfunctional" policies, which apply to all activities in the organization and serve to delineate the "core values" of the institution. "Functional policies" are the secondary layer of policy making which are primarily product-specific [and] can include lending (or credit) policies, by providing details of assessment criteria for loan products and services. ${ }^{35}$ While the EPs may be considered as an overarching policy that expresses the EPFI's commitment to environmental and social sustainability, the actual policies commercial lenders establish to assess risk in line with the EPs are functional in nature. As a result, these policies are "closely related to practice ... commercially sensitive and tend to remain confidential."

Therefore, while it is currently difficult to examine and compare the social and environmental risk policies enacted by commercial banks to assess project finance loan exposure, the conclusion can be made that each bank adopts and implements social and environmental risk management policies under the EPs in an organization-specific manner as an element of the firm's competitive strategy. This inevitably results in disparate models that operate through the application of differing variables and attributes assessed by each project lender, which presumably produces an uneven distribution of each EPFI's ability to capture relevant socio-environmental risks. Further, the ability of each EPFI to

\footnotetext{
34 Equator Principles, The Equator Principles Governance Association Rules, 7 (2010), available at: http://www.equator-principles.com/resources/ep_governance rules june 2010.pdf (last accessed: 1 December 2012).

${ }^{35}$ Andrea Coulson, A Benchmarking Study: Environmental Credit Risk Factors in the Pan European Banking Sector, ISIS ASSET MANAGEMENT 1, 7, (2002), available http://www.peblds.org/files/Publications/Articles/ISIS_Environmental_Credit_Risk_Factors.pdf (last accessed: 1 December 2012)

${ }^{36}$ Id.
} 
rate the quality of any syndicated project led by another EPFI is severely limited under such conditions of confidentiality. In sum, the EPs seem to lack a credible mechanism for standard setting, monitoring, and enforcement which are necessary in any self-regulating structure. ${ }^{37}$

Several scholars have identified NGO pressure related to environmental and social risks as the primary driving force behind the retreat of MDBs from the project financing sphere; ${ }^{38}$ the development of the EPs; ${ }^{39}$ and the current criticisms of the EPs. ${ }^{40}$ In order to build a more credible self-regulatory system controlled by commercial lenders, what is required is a set of procedures that are responsive to the potentialities of socio-environmental risk manifestation over the course of a large infrastructure financing project while modifying the behavior of the sponsor to mitigate beyond procedural compliance. Before suggesting possible ways to address the identified regulatory shortcomings, it is first necessary to understand the lender's risk exposure for non-recourse debt financing.

\section{Risk Structure for Non-Recourse Loans}

Infrastructure projects financed through commercial bank debt are situated within a unique context for evaluating environmental and social risks that may have an adverse effect on the lender. This refers primarily to the use of non-recourse financing. As Conley and Williams explain, this means that "lenders are repaid only through the revenues generated by the project. So even if the project sponsor (the borrower) is consistently one of the world's most profitable companies, the lending banks face particularized financial risks from anything that might slow down or derail the project." ${ }^{41}$ Without the ability to rely on the borrower's collateral, the mitigation and management of risks connected to disruptive social and environmental forces is necessary to ensure the lender's ability to recoup and profit from the loan provided. It is for this specific reason that "a direct link between the social and environmental risks of the project and the credit risks borne by the lenders $^{\prime 42}$ is found to exist in non-recourse financing arrangements.

\footnotetext{
${ }^{37}$ Forest ReINHARdt, Down to EARTH: ApPlying Business PRINCIPLES to ENVIRONMENTAL MANAGEMENT (2000).

${ }^{38}$ Conley \& Williams, supra note 2, at 11.

${ }^{39}$ Benjamin Richardson, Protecting Indigenous Peoples through Socially Responsible Investment, 6 INDIGEN. L. J. 205, 225 (2007).

${ }^{40}$ Bank Track, supra note 13 , at 2.

${ }^{41}$ Conley \& Williams, supra note 2 , at 3.

${ }^{42}$ Amalric, supra note 6 , at 9.
} 
Within the EP framework, the lender and borrower contract to allocate risk between them during the structuring of the financing project, which provides additional information as to the manner in which environmental and social risk is borne by the participants. As Esty explains, "project finance involves the creation of a legally independent project company financed with nonrecourse debt for the purpose of investing in a capital asset, usually with a single purpose and a limited life." ${ }^{43}$ This independent legal entity is called a Special Purpose Vehicle (SPV) and the capital structure of such entities is usually in the range of $70 \%$ bank syndicate leverage and $30 \%$ equity held by the sponsor(s). ${ }^{44}$ This necessitates high leverage ratios that operate to shield the non-project related assets of the sponsor from unknown risks that are prevalent in financing large infrastructure projects. The effect is that the "traditional risk-return tradeoff is altered to allow the equity investor to limit the downside risk while retaining the possibility of a high potential future payoff." ${ }^{\prime 45}$ Consequently, the sponsor only becomes fully exposed to the social and environmental risks of a project after the work becomes operational. This is because the SPV is able, at this point, to collect "income based on the usage of the facility," ${ }^{46}$ which can then be utilized to service the loan. Thus, as a result of the capital structure, the lender is primarily exposed to potential and unknown risks of environmental or social disruption that affect or delay a project before it becomes operational.

This unique nature of the project finance credit term has been investigated by Sorge and Gadanecz, whose research explores the differing relationship between maturity and credit spreads in the project finance sector in contrast to other types of syndicated loans and longer-term maturity bonds. Despite the fact that "project finance is characterized by much longer maturities compared to other forms of financing, ${ }^{\prime 47}$ Sorge and Gadanecz reject the positive correlation between longer maturities requiring higher risk premiums for the exposure to risk for a greater length of time. ${ }^{48}$ The authors instead note that project finance credit spreads are more likely characterized by a "hump-shaped" term structure:

[A]s a project nears completion, cash flows start to accrue and overall collateral value for the lenders increases. Moreover, most of the risks are

\footnotetext{
${ }^{43}$ Benjamin Esty, The Economic Motivations for Using Project Finance 1, 6 HARVARD BUSINESS SCHOOL (2003), available at: http://www.people.hbs.edu/besty/BCE\%20PF\%20Motivations\%202-14-03.pdf (last accessed: 1 December 2012).

${ }^{44}$ Id. at 7-8.

${ }^{45}$ Farrell, supra note 18 , at 555.

${ }^{46} \mathrm{Ng} \&$ Loosemore, supra note 32 , at 2.

${ }^{47}$ Marco Sorge, The Nature of Credit Risk in Project Finance, 91 BIS Q. REV. (December 2004).

${ }^{48}$ Marco Sorge \& Blaise Gadanecz, The Term Structure of Credit Spreads in Project Finance, 13 INT'L J. OF FIN. \& ECON. 68, 69 (2005).
} 
resolved in the early stages of the project. This would suggest that, while a longer maturity may imply an overall higher cumulative default risk, it is likely to only raise spreads at a decreasing rate ... ${ }^{49}$

The effect of acknowledging the hump-shaped structure of project finance initiatives for the lender is that an element of uncertainty in the assessment of social and environmental project risk and the temporal framework of the lender's heightened vulnerability may be identified.

Consider a basic example of a project with a thirty-year amortization period and an estimated ten-year period before the construction phase is complete and the project becomes operational. If the hump-shaped credit term is operationalized in the assessment of risk, the bank should be less concerned about mitigating socio-environmental risks that occur over the entire thirty-year amortization period. Instead, the bank's key focus should be on the ten year period, from project initiation to operation of the facility, because it is during this time that the bank's exposure is greatest in terms of leverage-to-asset ratios, and is further coupled with limited or no recourse to recover the proceeds of the loan. This also visibly demonstrates the timeframe in which banks are themselves most immediately vulnerable to disruptive activity from civil society groups and NGO campaigns. As the project progresses and becomes operational, the banks risk exposure will decline as recourse to the constructed assets of the sponsor become available. This is notable from the observation that an extension in the overall maturity of the project will increase the likely rate of default, but at a declining rate over time.

If the foregoing credit spread temporalities are compared to the EP risk management framework, it is apparent that the lender is primarily exposed to socio-environmental phenomena during the earliest stages of the project, yet the responsibility and costs of assessing, mitigating, and managing those same risks are allocated to the sponsor. Without direct exposure to risk, coupled with the high costs associated with socioenvironmental assessment and mitigation protocols, it can be argued that, from a cost/benefit analysis, it is in the best interest of the sponsor to mitigate only so far as to achieve procedural compliance with the EPs. The question then arises how the lender would be capable of mitigating the development of an unforeseen risk that is directly harmful to its interest but is beyond the scope of the Assessment, AP, Management system and contractual covenants of the sponsor. The lack of a credible mechanism for modifying the behavior of the risk mitigators (the sponsors) under the EPs is most glaring when the risk/reward ratio for the borrower becomes disaggregated from that of the lender.

Without a responsive governance mechanism incorporated into the EPs to help avoid these scenarios, the lender must ensure that the sponsor has meticulously categorized and

${ }^{49}$ Id. at 78. 
assessed the risks that impact the lender. Fully capturing socio-environmental risk at the outset of a project is seemingly an exercise in futility as unknown risks for any given project are as prevalent as known risks. But in order to capture those risks that can be identified, it is necessary to consider what "social or environmental risk" encapsulates from the perspective of the lender in the context of non-recourse financing.

The manner in which the EPs are drafted gives the impression that social and environmental risk are distinct categories that have only recently received due regard in the risk manager's assessment matrix. Environmental and social risks are not, however, distinct risk categories. It is for this reason that 'social or environmental risks' has been repeatedly conflated with "socio-environmental risks" throughout the course of this paper. Rather, they are subsets of and incorporated into the risks included in the two overarching types of risk which lenders are exposed to while financing large-scale infrastructure projects; direct risk and indirect risk. Direct project risks refer to anything that has an effect on the lender's ability to recoup its investment and interest over the course of the project. Indirect risk refers to risks external to the ability of the lender to recover financing costs, with the most prominent being reputational risk. Each of these two simplified categories of risk will be succinctly explored below to provide insight into what is an inherently complex web of exposure.

\section{Direct Risks}

For the purposes of this analysis, direct risks are defined as any social and environmental phenomena which have a direct consequence on the bank's ability to collect on the debt contract over the life of the project. This definition is exceptionally general, and necessarily so, as the obvious implication of mitigating environmental and social risk factors for international infrastructure projects is that exceptional attention must be paid to a complex range of factors regarding the specific geographic environment, host culture, the political economy, and shifting social opinions. Delineating specific socioenvironmental risk factors for any given project must be incorporated, as a result, into the overarching framework which lenders utilize to identify direct risks to ensure the return of, and on, the loan.

Farrell identifies five specific types of risk faced over the course of a project which must be properly identified and effectively allocated for mitigation. While examining these factors, it is worth recalling that despite the fact that mitigation responsibilities have been contractually allocated to the borrower, the underlying downside risk falls unevenly on the lender before the project becomes constructed and operational. It is argued that social or environmental phenomena affects the lender by increasing or decreasing the bank's exposure to the following forms of direct risk, listed and briefly defined below: 
1. Start-up cost risk - any delay that has the effect of increasing the lender's leverage ratios

2. Operating cost risk - the risk market value output will not be sufficient to service project debt or that output may deplete more rapidly than expected, etc.

3. Technology risk - risk of technology used to develop the final output

4. Market risk - the risk of loss of competitive position in output market

5. Political risk - risk of political interference. ${ }^{50}$

The Keystone XL pipeline provides a good illustration of the manner that socioenvironmental pressure can increase the lender's direct exposure, and also of the acknowledged unknown or elusive quality of risk in the project finance sector. Before President Obama interfered to delay advancement of the project due to social pressure grounded on environmental concerns, ${ }^{51}$ the US State Department's draft environmental risk assessment was signaling agreement with the project sponsor's assessment in that there would be "limited adverse environmental impacts." ${ }^{52}$ This is a clear example of a complete failure of the risk assessment employed by the participating parties to adequately capture and mitigate the level of risk posed by socio-environmental sources of pressure. Not only was the lender's exposure to political risk significantly amplified by environmental activism, but the lender's start-up risk exposure was concurrently increased. The extent to which the lending syndicate's assets-to-leverage ratios will be affected as a result of these understated or unforeseen risks can now only be assessed at an unknown point in the future when a resolution to this matter is found.

The Northern Gateway Pipeline is a further example, as detailed by the NGO ForestEthics in a report discussing the myriad of ways that downside risk to the viability of the project becoming operational has been intensified as a result of the sponsor's inability to fully

\footnotetext{
${ }^{50}$ Farrell, supra note 18 , at 550 .

51 CBC News, Harper 'disappointed' by Keystone Pipeline Delay, 13 November 2011, available at: http://www.cbc.ca/news/politics/story/2011/11/13/keystone-joe-oliver.html (last accessed: 1 December 2012).

52 David Lerman \& Nicole Gaouette, Keystone Pipeline Advances in Revised Environmental Study, BLOOMBERG (15 April 2011), available at: http://www.bloomberg.com/news/2011-04-15/keystone-pipeline-advances-in-revisedenvironmental-study.html (last accessed: 1 December 2012).
} 
appreciate and assess the project's liability to socio-environmental risk factors. ${ }^{53}$ During such a delay, the bank's leverage ratios are significantly increased while the timeframe for the project becoming operational has also increased; this dramatically amplifies the lender's overall risk exposure on the project.

It is not necessary to exhaustively consider the interaction of socio-environmental phenomena with each category of direct risk as it will vary depending on the idiosyncrasies of each project, the confidential standards employed by the lender, and the assessment and mitigation procedures employed by the sponsor. It is apparent from the foregoing examples that a failure to provide due consideration to the public's concern for social or environmental causes, and mitigating accordingly, directly challenges the lender's financing interests. In fact, an understanding of the analysis presented herein provides a general roadmap that can equip social groups that have sufficient information regarding the implementation schedule of a particular project to create aggressive strategies to target the direct vulnerabilities of the lender. Successful protection of the lender from direct socio-environmental risks surely requires the establishment of a regulatory mechanism under the EPs that is able to direct the sponsor's mitigation efforts towards the lender's exposure. But in order to arrive at this point, it is necessary to overcome the rather challenging hurdle of adequately capturing and assessing socio-environmental risk in a sector pervaded by a high level of "unknowable" risk. The following section will explore how the lender may begin approaching the question of capturing unknown socioenvironmental risk in order to develop more effective regulatory procedures, but it is first necessary to understand how the project lender is exposed to indirect socio-environmental risk.

\section{Indirect Risks}

Reputational risk can generally be considered the most important indirect risk for a lender in a project financing initiative. Reputational risk is indirect risk because it does not damage the lender's direct interest in the project, but the lender's association with the project produces long-term detrimental effects to the company on a much broader scale. As Case explains, "the largest cost component is likely to be 'opportunity cost' (that is, future business being lost to competitors displaying stronger ethical behaviour), meaning that the true financial loss is almost impossible to calculate." ${ }^{54}$ Reputational risk is thus often a "key policy driver" for the decision of major financial institutions to mitigate socio-

\footnotetext{
53 ForestEthics, Enbridge Northern Gateway Pipelines: Community Opposition and Investment Risks (2010), available at: http://www.forestethics.org/downloads/Enbr_investor_brief_oct2010_Final.pdf (last accessed: 1 December 2012).

${ }^{54}$ Phil Case, EnVironmental Risk Management and Corporate Lending: a Global Perspective 12 (1999).
} 
environmental risks. ${ }^{55}$ The importance of mitigating reputational risk exposure is provided by the EPs themselves, which may have been enacted primarily due to the reputational risk faced by financial institutions engaged in project financing. As Conley and Williams claim, "NGO pressure shamed them [EPFIs] into it."

The question must then be asked whether the EPs provide a mechanism for mitigating the lender's reputational risk, or whether the EPs themselves are the mechanism for mitigating such risk. It is apparent from the assessment of the EPs in Part I of this exposition that the procedures are a bare regulatory framework that essentially allocates responsibility over mitigating the bank's exposure to the project sponsor. This directly ties the reputation of the lender to the actions of the sponsor, for where the sponsor engages in egregious social or environmental behavior, the credibility of the lender is likely to come under attack by social interest groups. This occurred when MDBs were active participants in public infrastructure financing projects and it is already apparent under the EPs, as former partnering NGOs are heavily criticizing the entire initiative, ${ }^{57}$ as well as drawing attention to individual firm violations working under the EPs. ${ }^{58}$ Commercial banks that wish to avoid following the path of the MDBs, and instead aspire to increase their governance capacity and credibility of the project finance regulatory system, should be concerned with establishing and implementing a stronger regulatory mechanism into the EPs for accurately capturing, assessing, and mitigating the indirect exposure to lenders.

\section{E. Capturing, Predicting and Mitigating Environmental and Social Risks}

The foregoing analysis has attempted to assess the EPs in relation to the project lender's exposure to socio-environmental risk factors in order to evaluate whether the regulations are concordant with the structure of risk within the project finance sector. It is suggested that while the EPs are beneficial for commercial lenders in that the costs associated with the majority of the socio-environmental assessment and management process is shifted onto the project sponsor, the result is a risk management framework that temporally fixes the mitigation procedures to the earliest phases of the project. This is significant because the regulatory framework is unable to account for the lender's significant exposure to unknown or significantly amplified risks that may arise throughout the course of the credit term, especially before the project becomes operational. Without procedures responsive to unknown or amplified risks to the lender that are able to encourage the sponsor to

\footnotetext{
${ }^{55}$ Coulson, supra note 35 , at 9.

${ }^{56}$ Conley \& Williams, supra note 2 , at 17.

${ }^{57}$ See Bank Track, supra note 13.

${ }^{58}$ Bank Track, Dodgy Deals Map, available at: http://www.banktrack.org/dodgydealmap (last accessed: 1 December 2012).
} 
mitigate beyond the management plan enacted in the early stages of the project, it is also likely that commercial banks are providing financing for a cost lower than the level of risk actually assumed.

While these shortcomings in the regulatory framework have been identified, the problem of capturing unknown risks across a sector where social and environmental pressure and phenomena is highly varied and unpredictable depending on the project and location has also been discussed. As a correlation exists between socio-environmental risk exposure and the lender's ability to recover on the loan, the ability to overcome the problems of unknown and amplified risk presents the opportunity to develop regulatory mechanisms that are more closely tied to the lender's direct and indirect risk exposure. In short, stronger regulation to defend the lender's exposure on the loan may produce stronger socio-environmental risk mitigation and perhaps alleviate NGO campaign targeting. ${ }^{59}$

It is suggested that the problem with capturing unknown or amplified project risks stem from two general factors that the EPs do not seem to account for in assessing social and environmental phenomena. The first is that social and environmental phenomena are prone to change over the course of a project, and therefore a static risk model such as the EPs, which only focus on mitigating risks identified at project outset, cannot adequately reflect the shifting nature of risk. ${ }^{60}$ Second, "many social and environmental issues cannot be financially quantified using techniques familiar to financial institutions." ${ }^{161}$ Essentially, the risk management models employed by lenders and project sponsors to quantify and calculate risk provide a "structural limitation"62 to capturing the full extent of the social and environmental harms faced by the lender. Thus, while participants in the project finance field may have identified social and environmental risks as important considerations, the models used to delineate and account for these are poorly structured to capture social and environmental realities. This may explain the failure of mitigation procedures for projects such as the Keystone XL pipeline where the environmental impact statements and direct environmental risk exposure faced by the lending syndicate were noticeably disconnected in hindsight. If a structural limitation exists in the risk assessment protocols of the EPs, meaning the procedural models utilized cannot adequately "see" socio-environmental risk, perhaps supplementing project finance risk assessment models with a sociological understanding of risk can provide a corrective framework for addressing the identified regulatory gaps. Social scientific research on risk may provide a powerful tool for adequately predicting and capturing social and environmental risk.

${ }^{59}$ Amalric, supra note 6 , at 5.

${ }^{60} \mathrm{Ng} \&$ Loosemore, supra note 32 , at 5.

61 Benjamin Richardson, Putting Ethics into Environmental Law: Fiduciary Duties for Ethical Investment, 46 OSGOODE HALL L. J. 243, 246, (2008).

${ }^{62} / d$. 
The utility of adopting such an approach is illustrated by the fact that modern sociological theories offer the possibility of bridging the gap between the lender's intention to mitigate socio-environmental and a regulatory framework which is seemingly ill equipped to grasp the very nature of these types of risks due to structural limitations in the assessment protocols. Sociological theories of risk view social and environmental risks as entirely social processes. As Niklas Luhmann explains, "the outside world itself knows no risk, for it knows neither distinctions, nor expectations, nor evaluations, nor probabilities - unless self-produced by observer systems in the environment of other systems." ${ }^{63}$ If the risk management protocols of the EPs are viewed through the lens of the social analytical construct of the normal/deviant dichotomy, the shortcomings in the framework's inability to capture socio-environmental risks are immediately apparent. This is because the project lender and sponsor are approaching the perception, assessment, and mitigation of these risk factors utilizing normative risk management techniques filtered through their own normal form when these risk factors are instead attributable to a "deviant" secondary normality of NGOs other civil society groups. In attempting to mitigate social and environmental risks, commercial lenders "are dealing with the other side of the normal form - and it is only by referring to the other side of the normal form that it can be recognized as form." ${ }^{64}$

This inability to give form to the alternative normative reality of social activism can be seen in part of Canada's new anti-terrorism strategy, partially inspired by Northern Gateway pipeline activism, where environmental activists are now potentially liable to being labeled as "eco-extremist" terrorists. ${ }^{65}$ Because the normative forms utilized to capture socioenvironmental risk cannot give form to the deviant normative reality of social activism, actions conducted in accordance with these realities can only be described as radical, ideological, extreme, or a host of other deviant labels. While this type of aggressive labeling may prove beneficial for swaying public opinion in the press, the inability of project lenders and sponsors to look to the other side of the normal form will continue to ensure an inability to produce mitigation procedures that can adequately account for socio-environmental risks resulting from these radical, extreme, or ideological factors. If lenders understand how social and civil society groups understand, interpret, and act on risk themselves, others, and in particular socio-cultural and natural environments, they can incorporate this information into a regulatory framework that is directed at and responsive to these elements.

\footnotetext{
${ }^{63}$ NiKLAS LUHMANN, RISK: A SOCIOLOGICAL THEORY 6 (1993).

${ }^{64}$ Id. at VIII.

${ }^{65}$ Shawn McCarthy, Ottawa's new anti-terrorism strategy lists eco-terrorists as threats, THE GLOBE AND MAIL (6 September 2012) available at: http://m.theglobeandmail.com/news/politics/ottawas-new-anti-terrorismstrategy-lists-eco-extremists-as-threats/article2334975/?service=mobile (last accessed: 1 December 2012).
} 
While this theoretical perspective might address the structural shortcomings found under the EP framework, there is an open research question into which sociological risk model should be utilized and how to best incorporate this into the existing risk assessment framework. While it is beyond the scope of this paper to compare and evaluate sociological approaches to risk, one such model will be mentioned in order to demonstrate the utility such methods may have in addressing the shortcomings identified in this exposition. This is the social amplification of risk framework (SARF). As Kasperson et al explains,

[t]he theoretical starting-point is the assumption that "risk events," which might include actual or hypothesized accidents and incidents (or even new reports on existing risks), will be largely irrelevant or localized in their impact unless human beings observe and communicate them to others. SARF holds that, as a key part of the communication process, risk, risk events, and characteristics of both become portrayed through various risk signals (images, signs, symbols), which in turn interact with a wide range of psychological, social, institutional, or cultural processes in ways that intensify or attenuate perceptions of risk and its manageability. The experience of risk therefore is not only an experience of physical harm but the result of processes by which groups and individuals learn to acquire or create interpretations of risk. ${ }^{66}$

The SARF framework examines the connections between a risk event and the causal and temporal framework in which it interacts through a variety of sources "triggering social stations of amplification, initiating individual stations of amplification, and triggering behavioural reactions ${ }^{\prime 67}$ related to the interpretation of risk. As a result, with reference to the earlier discussion of the Keystone XL pipeline, the SARF method may provide the tools to explain the "process by which certain hazards and events that experts assess as relatively low in risk can become a particular focus of concern and sociopolitical activity within a society." ${ }^{\prime 68}$ This is because SARF is a not temporally fixed, like the procedures under the EPs, as it aims "to describe the various dynamic social processes underlying risk perception and response." ${ }^{\prime 69}$ This framework approaches risk in a manner which may analytically account for the manner in which socio-environmental risk manifests to

\footnotetext{
${ }^{66}$ Kasperson et al, The Social Amplification of Risk: Assessing Fifteen Years of Research and Theory, in THE SOCIAL AMPLIFICATION OF RISK 13, 15 (Pidgeon et. al. eds., 2003).

${ }^{67}$ Breakwell \& Barnett, Social Amplification of risk and the Layering Method, in THE SOCIAL AMPLIFICATION OF RISK 80 (Pidgeon et al. eds., 2003).

${ }^{68}$ Kasperson, supra note 66, at 13.

${ }^{69}$ Id. at 13.
} 
challenge the interests of commercial lenders in the project finance sector. Although more research is required to assess the viability of integrating SARF or other sociological models of risk into the EP risk assessment protocols, at the very least, this discussion can demonstrate the value that a shift in perspective can have for increasing the ability of commercial lenders to capture social and environmental risk factors that directly or indirectly affect their interests.

\section{F. Conclusion}

This paper has attempted to conceptualize, contextualize and classify private project finance governance under the EPs in order to better understand how social and environmental phenomena are captured and allocated for mitigation between the lender and sponsor. Particular attention has been paid to the liabilities and vulnerabilities of the lender, and the ability to provide an effective governance strategy through the mitigation of these risks. The general conclusion agrees with academic research on risk management practice in Public, Private Partnership projects, that "risk management practices are highly variable, intuitive, subjective, and unsophisticated." ${ }^{70}$ Furthermore, the EP framework is significantly limited in addressing the particular vulnerabilities of the lender to socioenvironmental risks over the non-recourse credit term. It was also suggested that the identified gaps in the regulatory framework may be partly addressed through the application of social scientific methods to provide the lender with an effective method for capturing its exposure to socio-environmental risk so that it may direct its attention to modifying the behavior of the sponsor to implement applicable mitigation procedures. Although this analysis has proceeded in the face of a dearth of empirical knowledge on lender-specific socio-environmental risk assessment protocols, potentially related to the lack of firm transparency in the sector, it provides a stepping stone for specifically identifying and characterizing socio-environmental risk and an avenue for scholarly research to further assess the viability of applying social scientific risk management frameworks in the sector of private project finance.

\footnotetext{
${ }^{70} \mathrm{Ng}$ \& Loosemore, supra note 32 , at 2.
} 